\title{
Factors Affecting the Knowledge and Practice of Drug Management among Healthcare Workers in Primary Health Centers in South-East, Nigeria
}

\author{
Chinyere C. Okeke, Benjamin S. C. Uzochukwu, Elias C. Aniwada, Chinedu A. Idoko, \\ Kassy W. Chukwukasi, Anne C. Ndu
}

Department of Community Medicine, University of Nigeria, Enugu Campus, Enugu, Nigeria

Email: chinyereokeke83@yahoo.com

How to cite this paper: Okeke, C.C., Uzochukwu, B.S.C., Aniwada, E.C., Idoko, C.A., Chukwukasi, K.W. and Ndu, A.C. (2021) Factors Affecting the Knowledge and Practice of Drug Management among Healthcare Workers in Primary Health Centers in South-East, Nigeria. Health, 13, 1097-1111.

https://doi.org/10.4236/health.2021.131008

Received: July 14, 2021

Accepted: October 23, 2021

Published: October 26, 2021

Copyright $\odot 2021$ by author(s) and Scientific Research Publishing Inc. This work is licensed under the Creative Commons Attribution International License (CC BY 4.0).

http://creativecommons.org/licenses/by/4.0/

\begin{abstract}
The knowledge of health workers regarding their management of drugs is very important in ensuring good health. One of the major indices of the performance of primary health care (PHC) remains improved access to essential drugs as they are the link between patients and health services. Consequently, their availability or absence will contribute to a positive or negative impact on health. This was a quasi-experimental study, carried out in Anambra state, which compared the intervention and control groups following the training and provision of drug management tools to $\mathrm{PHC}$ workers in the intervention group. A multi-stage sampling technique was used to select 264 health workers from 132 health centers from two senatorial zones in the State, one acting as a control group and the other as an intervention group. Data was collected using a pre-tested in-depth interview guide and semi-structured interviewer administered questionnaire. Statistical analysis was conducted using SPSS at a statistical significance level of $\mathrm{p}$ value less than 0.05 , while qualitative data was analyzed using N-Vivo. Several factors such as age, sex, educational qualification, cadre of staff, years of practice and $\mathrm{PHC}$ workers' previous training were identified as affecting the knowledge and practice of drug management. The majority $(72.0 \%$ and $71.2 \%)$ in intervention and control groups respectively said inadequate information or lack of knowledge was the main reason for poor practices while the proportion with low interest of health workers for drug management was (38.5\%) for intervention and (59.8\%) for the control group and the difference between the groups was statistically significant $(\mathrm{p}=$ 0.034). In conclusion, this study has shown that age, sex, educational qualification, cadre of staff, years of practice and PHC workers' previous training
\end{abstract}


were factors associated with health workers' knowledge and practice of drug management. The study recommends the development of Aide Memoire and conduct of training and retraining on drug management to improve both knowledge and practice of drug management in PHCs in Nigeria.

\section{Keywords}

Training, Drug Management, Primary Health Workers, Nigeria

\section{Introduction}

Drug management is a key component of pharmaceutical services. The availability of medicines contributes to the improved quality of pharmaceutical services. Drug management is the set of practices aimed at ensuring the timely availability and appropriate use of safe, effective, quality medicines and related products and services in any healthcare setting [1]. Efficient drug management is the key strategy in reducing the costs of drugs and ensuring their availability in healthcare facilities [2]. One of the major indices of the performance of the primary health care (PHC) delivery remains improved access to essential drugs [3].

The knowledge of health workers regarding their management of drugs is very important in ensuring good health. In a cross-sectional study by some authors in Tanzania to assess the knowledge of the practice of pharmaceutical management among health workers from nine hospitals, it was noted that six drug store managers had poor knowledge of quantification concept, seven did not apply drug store supply logistics system, and all nine of them had inadequate knowledge of the concept of procurement [4]. In another study carried out to assess HIV/AIDS drug procurement and supply chain management; adequate human resources with the necessary skills, adequate and timely information flow from facilities to central medical stores, adequate distribution material and cost reduction in centralized purchasing were identified as strengths to drug management. On the other hand, corruption, lack of political will, unavailability of funds and lack of good storage conditions for drugs are some of the weaknesses to drug management [5].

Lack of good knowledge of drug management in the PHCs has led to: poor selection of medicines, without consideration for relative efficacy, cost-effectiveness or local availability; inefficient procurement practices, resulting in non-availability, inadequate quality, wastage, or use of unnecessarily expensive medicines; prescribing not in accordance with standard treatment protocols; poor dispensing practices resulting in medication errors, and patients' lack of knowledge about dosing schedules; patients not adhering to dosing schedules and treatment advice [6]. All these affect the availability, safety and quality of health care and the wastage of scarce drugs in the PHCs.

There have been few studies carried out in Nigeria, especially in the South Eastern region, assessing the knowledge and practices of primary health centre 
workers on drug management, leaving a significant gap in knowledge and practice in the South-East. There is also paucity of studies that have carried out evaluation of factors and effects of training on drug management in public health facilities in this country. Whereas quite a number of studies have shown that health workers have poor knowledge of the various components of drug management and as such have very poor practices too [4] [7] [8].

This study then seeks to ascertain the factors affecting the knowledge and practice of drug management among primary health care workers involved in drug management in the primary health centers in Anambra state. This provides evidence for informed decision-making and policy formulation with regards to drug management in the state.

\section{Methods}

The study was conducted in selected primary health centers in Anambra state, Nigeria. Anambra state is located in the southeast geopolitical zone of Nigeria.

\subsection{Study Design}

This is a quasi-experimental study that compared the intervention and control groups "before and after" an intervention carried out on health workers in PHCs in Anambra state. The intervention included: training on drug management and the provision of drug registers and stock cards to the selected health facilities for the management of essential drugs.

The study was carried out in three phases:

- A Pre-intervention phase during which base line data was collected using a structured interviewer questionnaire and observation checklist. Also in-depth interviews were conducted with the pharmacist-in-charge of the state central medical stores, director pharmacy at the state ministry of health and the person in charge of PHCs in the state ministry of local government.

- Intervention phase, where training was conducted, stock cards and drug registers were also provided in the selected PHCs.

- Post-intervention phase, during which the outcome of the intervention given was assessed using a structured interviewer-administered questionnaire and observation checklist.

\subsection{Study Population}

The study population was made up of primary health care workers involved with selecting, quantifying, procuring, storing and dispensing drugs in the health centres selected for the study. Those included were full time primary health care workers involved in drug management in the selected primary health centres and their assistant. The exclusion criteria included those eligible, but will be retiring within six months from the training period because they will not be around for the post intervention data collection, those who are sick, on leave, or did not give consent to participate in the study. 
Case group: comprised of health care workers involved in drug management in the primary health centres selected from one senatorial group for the study and met the inclusion criteria. While the control group comprised of same cadre of workers but from a different senatorial zone.

Sample size was determined using the formula for estimating sample size for comparing two proportions of equal size in a population less than ten thousand [9].

$$
\begin{aligned}
& n=\frac{\left(Z_{\alpha}+Z_{\beta}\right)^{2} \times p_{1}\left(1-p_{1}\right)+p_{2}\left(1-p_{2}\right)}{\left(p_{2}-p_{1}\right)^{2}} \\
& n=119.133
\end{aligned}
$$

On adding 10\% for non-response, we have approximately 132 health workers per study group.

\subsection{Sampling Technique}

The study used a multi-stage sampling technique. In Stage 1; Anambra State was selected randomly using the balloting methods from all the 5 states in the South East. Stage 2; Two out of three senatorial zones in the state were selected by simple random sampling using the balloting method to be the case group and the control groups respectively. Stage 3; 66 PHCs were selected by simple random sampling using balloting method from the PHCs in the case group and the PHCs in the control group. Stage 4; Health officer-in-charge of drugs and one assistant were recruited for the study from the selected PHCs. Balloting was used to select one assistant where more than one exists.

\subsection{Data Collection}

Six research assistants were trained for 3 days by the principal investigator, on the study objectives, survey methods, completion of the questionnaires and observation checklist. Instruments for the study were pre-tested In-depth interview guide and a semi-structured interviewer administered questionnaire. Baseline data was collected for 2 weeks from primary health workers using the self-administered questionnaire.

\section{Intervention phase}

The training was based on course content adapted from WHO hand book for drug supply training manual at the first level health facility [10]. The training was conducted by two medical doctors who had received the WHO training. The participants were divided into 4 batches of about 35 participants each for ease of interaction and active participation. The training was conducted in different days and each session lasted for 7 hours, using both didactic and participatory learning methods, with participant's manuals and charts given to the participants after the training for reference and refresher purposes.

\section{Post Intervention Stage}

Involved the comparative assessment of the intervention and the control 
group through a post intervention data collected using same questionnaire used at the pre-intervention stage and the residual gain in drug management knowledge and practice was determined. It was carried out six months after the intervention to allow for change to occur in the drug management practices.

Quantitative data was coded, tabulated and analyzed using the software: IBM SPSS version 22, while the qualitative data was transcribed on the same day of interview and analyzed using N-Vivo software.

\section{Variables are divided into:}

Independent/ predictor variables: Socio-demographic variables including age, sex, educational level, occupation, marital status, cadre of staff and years of practice.

Dependentloutcome variables include: Knowledge on drug management; Practice on drug management; Factors influencing drug management.

Statistical analysis. The mean knowledge score will be compared using Student $\mathrm{t}$ test at baseline and after 6 months. There are 19 knowledge questions; correct answer will be coded asland wrong answer will be coded as zero. Good knowledge is any score greater than or equal to10, while poor knowledge is a score less than 10.

The practices by the respondents will be measured by the proportion of those that practice the questions asked at baseline and at six months after intervention for both study and control groups. They will be equally compared, and this will be subjected to the Chi-square tests of significance. The mean knowledge score will be compared using Student $t$ test at baseline and after six months. There are 28 practice questions; those practicing it will be coded as 1 and those not practicing it will be coded as zero. A score of 15 and more is good practice, while a score less than 15 is poor practice.

\subsection{Ethical Considerations}

Consent was sought and obtained from the LGA authorities, head of the facility and each of the participants. Written ethical clearance was obtained from the Ethics Committee of University of Nigeria Teaching Hospital (UNTH), Enugu. Requests for permission were from Health facility heads in the selected facilities. Written informed consent was obtained from the Primary Health Care workers. Confidentiality was assured by making the study as anonymous as possible.

\section{Findings}

A total of 132 health workers participated in the quantitative aspect of the study both in the pre and post intervention phases. A total of 264 questionnaires distributed were retrieved giving a response rate of $100 \%$, while the six top health workers directly involved with drugs management in the state responded to the interview. A total of the 132 checklists used to collect information from the health centers were also retrieved. The results therefore are based on the analysis of the 264 questionnaires, the 132 checklists and 6 IDIs. 


\subsection{Socio-Demographic Characteristics}

Table 1 shows socio-demographic characteristics of respondents. Most of the health workers were aged over 35 years (87.9\% of the intervention and $85.6 \%$ of the control group), with an overall mean age of $43.4 \pm 7.92$ and majority of them were females (97.7\% and $96.2 \%)$. A higher proportion of the health workers attended school of health technology $(51.5 \%$ and $58.3 \%)$ and were mostly CHEWs/JCHEWs (42.4\% and 49.2\%). Most of the health workers had worked for more than 10 years $(90.2 \%$ and $87.9 \%)$. None of the socio-demographic variables of the respondents had a statistically significant difference between the health care workers in the intervention and control groups.

\subsection{Factors Responsible for Drug Management Practices}

Table 2 shows the factors responsible for the drug management practices of the health workers in the state. At baseline, majority (72.0\% and $71.2 \%)$ in intervention and control groups respectively said inadequate information or lack of

Table 1. Socio - demographic characteristics of healthcare workers.

\begin{tabular}{|c|c|c|c|c|}
\hline Variable & $\begin{array}{l}\text { Intervention } \\
\quad(\mathrm{N}=132) \\
\text { Frequency (\%) }\end{array}$ & $\begin{array}{c}\text { Control } \\
(\mathrm{N}=132) \\
\text { Frequency (\%) }\end{array}$ & $\begin{array}{c}\text { Total } \\
(\mathrm{N}=264) \\
\text { Frequency }(\%)\end{array}$ & $\chi^{2}(\mathrm{p}$ value $)$ \\
\hline \multicolumn{5}{|l|}{ Age (Years) } \\
\hline$<35$ & $16(12.1)$ & $19(14.4)$ & $35(13.3)$ & \\
\hline$\geq 35$ & $116(87.9)$ & $113(85.6)$ & $229(86.7)$ & $\mathrm{T}$ test \\
\hline Mean $\pm(S D)$ years & $43.2(7.7)$ & $43.58(8.12)$ & $43.4(7.37)$ & $0.543(0.588)$ \\
\hline \multicolumn{5}{|l|}{ Sex } \\
\hline Male & $3(2.3)$ & $5(3.8)$ & $8(3.0)$ & $0.516(0.473)$ \\
\hline Female & $129(97.7)$ & $127(96.2)$ & $256(97.0)$ & \\
\hline \multicolumn{5}{|l|}{$\begin{array}{l}\text { Highest educational } \\
\text { qualification received }\end{array}$} \\
\hline University & $23(17.4)$ & $25(18.9)$ & $48(18.2)$ & $2.346(0.309)$ \\
\hline Nursing/Midwifery school & $41(31.1)$ & $30(22.7)$ & $71(26.9)$ & \\
\hline School of Health Technology & $68(51.5)$ & $77(58.3)$ & $145(54.9)$ & \\
\hline \multicolumn{5}{|l|}{ Cadre of Staff } \\
\hline Nursing Officer & $45(34.1)$ & $39(29.5)$ & $84(31.8)$ & \\
\hline $\mathrm{CHO}$ & $22(16.7)$ & $15(11.4)$ & $37(14.0)$ & $3.150(0.369)$ \\
\hline CHEW/JCHEW & $56(42.4)$ & $65(49.2)$ & $121(45.8)$ & \\
\hline Health Attendant & $9(6.8)$ & $13(9.8)$ & $22(8.3)$ & \\
\hline \multicolumn{5}{|l|}{ Years of practice } \\
\hline$<10$ years & $13(9.8)$ & $16(12.1)$ & $29(11.0)$ & $1.391(0.708)$ \\
\hline$\geq 10$ years & $119(90.2)$ & $116(87.9)$ & $235(89.0)$ & \\
\hline Median years of practice & 15 & 15 & 15 & \\
\hline
\end{tabular}


Table 2. Factors responsible for drug management practices.

\begin{tabular}{|c|c|c|c|c|c|c|}
\hline \multirow{4}{*}{ Variable } & \multicolumn{3}{|c|}{ Baseline } & \multicolumn{3}{|c|}{ After Intervention } \\
\hline & \multirow{2}{*}{$\begin{array}{c}\text { Intervention } \\
\mathrm{N}=132\end{array}$} & \multirow{2}{*}{$\begin{array}{l}\text { Control } \\
\mathrm{N}=132\end{array}$} & \multirow{3}{*}{$\chi^{2}(\mathrm{p}$ value $)$} & Intervention & Control & \multirow{3}{*}{$x^{2}$ (p value) } \\
\hline & & & & $\mathrm{N}=132$ & $\mathrm{~N}=132$ & \\
\hline & Freq (\%) & Freq $(\%)$ & & Freq (\%) & Freq $(\%)$ & \\
\hline Lack of materials & $86(85.2)$ & $101(76.5)$ & $0.030(0.862)$ & $121(91.7)$ & $91(68.9)$ & $21.553(0.000)$ \\
\hline Inadequate human resources/increased workload & $88(66.7)$ & $100(75.8)$ & $0.704(0.401)$ & $123(93.2)$ & $98(74.2)$ & $17.363(0.000)$ \\
\hline Insufficient financial resources & $93(70.5)$ & $92(69.7)$ & $0.930(0.335)$ & $116(87.9)$ & $92(69.7)$ & $13.055(0.000)$ \\
\hline Lack of incentives & $76(57.6)$ & $77(58.3)$ & $0.486(0.486)$ & $113(85.6)$ & $81(61.4)$ & $19.907(0.000)$ \\
\hline Inadequate information/knowledge & $95(72.0)$ & $94(71.2)$ & $0.579(0.447)$ & $125(94.7)$ & $101(76.5)$ & $17.707(0.000)$ \\
\hline Poor supervision & $87(65.9)$ & $98(74.2)$ & $0.014(0.904)$ & $121(91.7)$ & $96(72.7)$ & $16.178(0.000)$ \\
\hline Low interest of workers on drug management & $64(38.5)$ & $79(59.8)$ & $4.519(0.034)$ & $101(76.5)$ & $87(65.9)$ & $3.622(0.077)$ \\
\hline Attended drug training course/seminar & $12(9.1)$ & $19(14.4)$ & $2.467(0.116)$ & $131(99.2)$ & $28(21.2)$ & $0.167(<0.001)$ \\
\hline Last time training was received & $\mathrm{N}=12$ & $\mathrm{~N}=19$ & & $\mathrm{~N}=131$ & $\mathrm{~N}=\mathbf{2 8}$ & \\
\hline$<10$ years & $4(33.3)$ & $7(36.8)$ & $0.040(0.842)$ & $131(100.0)$ & $11(39.3)$ & FT \\
\hline$\geq 10$ years & $8(66.7)$ & $12(63.2)$ & & $0(0.0)$ & $17(60.7)$ & 0.000 \\
\hline
\end{tabular}

knowledge was the main reason for poor practices while the proportion with low interest of health workers for drug management was (38.5\%) for intervention and $(59.8 \%)$ for control group and the difference between the groups was statistically significant $(\mathrm{p}=0.034)$. Only $9.1 \%$ of the intervention group and $14.4 \%$ of the control group had attended drug training in the past and majority of them had it over 10 years ago with statistical significant difference between the groups $(p=0.040)$. Post intervention, majority of the respondents from the intervention group responded that all the factors mentioned were important for drug management and the difference between both groups were statistically significant for all factors.

\subsection{Factors Associated with Knowledge and Practice of Drug Management among Primary Health Center Workers}

Table 3 shows the association between the socio demographic variables and the mean knowledge score of drug management which was found to be poor all through before the intervention but none of this was significant. Post intervention, the knowledge score for the intervention group improved and was statistically significant for cadre of staff with a p value of 0.038 and the reverse was the case for the control group, where those with poor knowledge were more for age and years of practice, the difference was significant at a $p$ values of 0.008 and 0.007 respectively.

Table 4 shows the association between the socio-demographic variables and the practice score of drug management. More of the respondents from both groups had poor practices prior to intervention and the difference between the two groups was statistically significant for age of the control group with a $p$ value 
Table 3. Factors associated with knowledge and practice of drug management among primary health center workers.

\begin{tabular}{|c|c|c|c|c|c|c|c|c|}
\hline \multirow{4}{*}{ Variable } & \multicolumn{4}{|c|}{ Baseline } & \multicolumn{4}{|c|}{ After intervention } \\
\hline & \multicolumn{2}{|c|}{ Intervention } & \multicolumn{2}{|c|}{ Control } & \multicolumn{2}{|c|}{ Intervention } & \multicolumn{2}{|c|}{ Control } \\
\hline & Good & Poor & Good & Poor & Good & Poor & Good & Poor \\
\hline & n (\%) & n (\%) & n (\%) & n (\%) & n (\%) & n (\%) & n (\%) & n (\%) \\
\hline Age $<35$ & $2(12.5)$ & $14(87.5)$ & $8(42.1)$ & $11(57.9)$ & $12(75.0)$ & $4(25.0)$ & $3(15.8)$ & $16(84.2)$ \\
\hline Age $\geq 35$ & $29(25.0)$ & $87(75.0)$ & $34(30.1)$ & $79(69.9)$ & $85(73.3)$ & $31(26.7)$ & $55(48.7)$ & $58(51.3)$ \\
\hline$\chi^{2}$ (p value) & \multicolumn{2}{|c|}{$1.223(0.269)$} & \multicolumn{2}{|c|}{$1.083(0.269)$} & \multicolumn{2}{|c|}{$0.021(0.884)$} & \multicolumn{2}{|c|}{$7.140(0.008)$} \\
\hline \multicolumn{9}{|l|}{ Sex } \\
\hline Male & $1(33.3)$ & $2(66.7)$ & $2(40.0)$ & $3(60.0)$ & $3(100.0)$ & $0(0.0)$ & $2(40.0)$ & $3(60.0)$ \\
\hline Female & $30(23.3)$ & $99(76.7)$ & $40(31.5)$ & $87(68.5)$ & $94(72.9)$ & $35(27.1)$ & $56(44.1)$ & $71(55.9)$ \\
\hline$\chi^{2}$ (p value) & \multicolumn{2}{|c|}{$0.166(0.684)$} & \multicolumn{2}{|c|}{$0.160(0.684)$} & \multicolumn{2}{|c|}{$1.108(0.293)$} & \multicolumn{2}{|c|}{$0.033(0.856)$} \\
\hline \multicolumn{9}{|l|}{ Educational qualification } \\
\hline University & $5(21.7)$ & $18(78.3)$ & $10(40.0)$ & $15(60.0)$ & $20(87.0)$ & $3(13.0)$ & $16(64.0)$ & $9(36.0)$ \\
\hline Nurse/midwifery school & $14(34.1)$ & $27(65.9)$ & $11(36.7)$ & $19(63.3)$ & $33(80.5)$ & $8(19.5)$ & $10(33.3)$ & $20(66.7)$ \\
\hline School of health & $12(17.6)$ & $56(82.4)$ & $21(27.3)$ & $56(72.7)$ & $44(64.7)$ & $24(35.3)$ & $32(41.6)$ & $45(58.4)$ \\
\hline$\chi^{2}$ (p value) & \multicolumn{2}{|c|}{$3.922(0.141)$} & \multicolumn{2}{|c|}{$1.830(0.401)$} & \multicolumn{2}{|c|}{$5.864(0.053)$} & \multicolumn{2}{|c|}{$5.631(0.060)$} \\
\hline \multicolumn{9}{|l|}{ Years of practice } \\
\hline$<10$ years & $2(15.4)$ & $11(84.6)$ & $4(25.0)$ & $12(75.0)$ & $8(61.5)$ & $5(38.5)$ & $2(12.5)$ & $14(87.5)$ \\
\hline$\geq 10$ years & $29(24.4)$ & $90(75.6)$ & $38(32.8)$ & $78(67.2)$ & $89(74.8)$ & $30(25.2)$ & $56(48.3)$ & $60(51.7)$ \\
\hline$\chi^{2}$ (p value) & \multicolumn{2}{|c|}{$0.527(0.468)$} & \multicolumn{2}{|c|}{$0.390(0.532)$} & \multicolumn{2}{|c|}{$1.056(0.304)$} & \multicolumn{2}{|c|}{$7.306(0.007)$} \\
\hline \multicolumn{9}{|l|}{ Cadre of staff } \\
\hline Nursing Officer & $16(35.6)$ & $29(64.4)$ & $15(38.5)$ & $24(61.5)$ & $39(86.7)$ & $6(13.3)$ & $17(43.6)$ & $22(56.4)$ \\
\hline $\mathrm{CHO}$ & $5(22.7)$ & $17(77.3)$ & $3(20.0)$ & $12(80.0)$ & $12(54.5)$ & $10(45.5)$ & $10(66.7)$ & $5(33.3)$ \\
\hline CHEW/JCHEW & $9(16.1)$ & 47 (83.9) & $21(32.3)$ & $44(67.7)$ & $40((71.4)$ & $16(28.6)$ & $29(44.6)$ & $36(55.4)$ \\
\hline Health attendant & $1(11.1)$ & $8(88.9)$ & $3(23.1)$ & $10(76.9)$ & $6(66.7)$ & $3(33.3)$ & $2(15.4)$ & $11(84.6)$ \\
\hline$\chi^{2}$ (p value) & \multicolumn{2}{|c|}{$6.135(0.105)$} & \multicolumn{2}{|c|}{$2.224(0.527)$} & \multicolumn{2}{|c|}{$8.399(0.038)$} & \multicolumn{2}{|c|}{$7.463(0.059$} \\
\hline
\end{tabular}

Table 4. Association between the socio-demographic variables and the practice score of drug management.

\begin{tabular}{|c|c|c|c|c|c|c|c|c|}
\hline \multirow{3}{*}{ Variable } & \multicolumn{2}{|c|}{ Intervention } & \multicolumn{2}{|c|}{ Control } & \multicolumn{2}{|c|}{ Intervention } & \multicolumn{2}{|c|}{ Control } \\
\hline & Good & Poor & Good & Poor & Good & Poor & Good & Poor \\
\hline & n (\%) & n (\%) & n (\%) & n (\%) & n (\%) & n (\%) & n (\%) & n (\%) \\
\hline Age $<35$ & $6(37.5)$ & $10(62.5)$ & $9(47.4)$ & $10(52.6)$ & $10(62.5)$ & $6(37.5)$ & $6(31.6)$ & $13(68.4)$ \\
\hline \multirow[t]{2}{*}{ Age $\geq 35$} & $34(29.3)$ & $82(70.7)$ & $26(23.0)$ & $87(77.0)$ & $71(61.2)$ & $45(38.8)$ & $43(38.1)$ & $70(61.9)$ \\
\hline & \multicolumn{2}{|c|}{$\chi^{2}=0.447, \mathrm{p}=0.504$} & \multicolumn{2}{|c|}{$\chi^{2}=4.953, p=0.026$} & \multicolumn{2}{|c|}{$\chi^{2}=0.010, \mathrm{p}=0.921$} & \multicolumn{2}{|c|}{$\chi^{2}=0.292, p=0.589$} \\
\hline \multicolumn{9}{|l|}{ Sex } \\
\hline Male & $1(33.3)$ & $2(66.7)$ & $2(40.0)$ & $3(60.0)$ & $0(0.0)$ & $3(100.0)$ & $2(40.0)$ & $3(60.0)$ \\
\hline \multirow[t]{2}{*}{ Female } & $39(30.2)$ & $90(69.8)$ & $33(26.0)$ & $94(74.0)$ & $81(61.4)$ & $48(37.2)$ & $47(37.0)$ & $80(63.0)$ \\
\hline & \multicolumn{2}{|c|}{$\chi^{2}=0.013, p=0.908$} & \multicolumn{2}{|c|}{$\chi^{2}=0.485, p=0.486$} & \multicolumn{2}{|c|}{$\chi^{2}=4.876, p=0.027$} & \multicolumn{2}{|c|}{$\chi^{2}=0.018, p=0.892$} \\
\hline
\end{tabular}




\section{Continued}

\begin{tabular}{|c|c|c|c|c|c|c|c|c|}
\hline \multicolumn{9}{|l|}{ Educational qualification } \\
\hline University & $5(21.7)$ & $18(78.3)$ & $7(28.0)$ & $18(72.0)$ & $12(52.2)$ & $11(47.8)$ & $10(40.0)$ & $15(60.0)$ \\
\hline Nurse/midwifery school & $13(31.7)$ & $28(68.3)$ & $11(36.7)$ & $19(63.3)$ & $25(61.0)$ & $16(39.0)$ & $11(36.7)$ & $19(63.3)$ \\
\hline \multirow[t]{2}{*}{ School of health } & $22(32.4)$ & $46(67.6)$ & $17(22.1)$ & $60(77.9)$ & $44(64.7)$ & $22(35.3)$ & $28(36.4)$ & $49(63.6)$ \\
\hline & \multicolumn{2}{|c|}{$\chi^{2}=0.972, p=0.615$} & \multicolumn{2}{|c|}{$\chi^{2}=2.393, \mathrm{p}=0.302$} & \multicolumn{2}{|c|}{$\chi^{2}=1.142, p=0.565$} & \multicolumn{2}{|c|}{$\chi^{2}=0.110, p=0.946$} \\
\hline \multicolumn{9}{|l|}{ Years of practice } \\
\hline$<10$ years & $3(23.1)$ & $10(76.9)$ & $3(18.8)$ & $13(81.2)$ & $7(53.8)$ & $6(46.2)$ & $6(37.5)$ & $10(62.5)$ \\
\hline \multirow[t]{2}{*}{$\geq 10$ years } & $37(31.1)$ & $82(68.9)$ & $32(27.6)$ & $84(72.4)$ & $74(62.2)$ & $45(37.8)$ & $43(37.1)$ & $73(62.9)$ \\
\hline & \multicolumn{2}{|c|}{$\chi^{2}=0.001, p=0.974$} & \multicolumn{2}{|c|}{$\chi^{2}=0.020, p=0.888$} & \multicolumn{2}{|c|}{$\chi^{2}=344, \mathrm{p}=0.558$} & \multicolumn{2}{|c|}{$\chi^{2}=0.001, p=0.973$} \\
\hline \multicolumn{9}{|l|}{ Cadre of staff } \\
\hline Nursing Officer & $13(28.9)$ & $32(71.1)$ & $12(30.8)$ & $27(69.2)$ & $26(57.8)$ & $19(42.2)$ & $13(33.3)$ & $26(66.7)$ \\
\hline $\mathrm{CHO}$ & $9(40.9)$ & $13(59.1)$ & $6(40.0)$ & $9(60.0)$ & $13(59.1)$ & $9(40.9)$ & $6(40.0)$ & $9(60.0)$ \\
\hline CHEW/JCHEW & $16(28.6)$ & $40(71.4)$ & $14(21.5)$ & $51(78.5)$ & $38(67.9)$ & $18(32.1)$ & $27(41.5)$ & $38(58.5)$ \\
\hline \multirow[t]{2}{*}{ Health attendant } & $2(22.2)$ & $7(77.8)$ & $3(23.1)$ & $10(76.9)$ & $5(55.6)$ & $4(44.4)$ & $3(23.1)$ & $10(76.9)$ \\
\hline & \multicolumn{2}{|c|}{$\chi^{2}=1.572, p=0.666$} & \multicolumn{2}{|c|}{$\chi^{2}=2.667, \mathrm{p}=0.446$} & \multicolumn{2}{|c|}{$\chi^{2}=2.375, \mathrm{p}=0.498$} & \multicolumn{2}{|c|}{$\chi^{2}=1.935, p=0.586$} \\
\hline
\end{tabular}

of 0.026 . In the post intervention, the intervention group had better practice scores and difference between the practices and was statistically significant for the sex of the respondents $(\mathrm{p}=0.027)$ while the control group had more poor practice scores but the difference between the scores was not statistically significant.

Table 5 shows the knowledge and practice score of either group of health workers before and after the intervention. The intervention group following intervention showed tremendous increase in the proportion of health workers with knowledge score $\geq 50 \%$ compared to their proportion pre-intervention whereas [from $31(23.5 \%)$ to $97(73.5 \%)$ ], the control group showed little change in knowledge before and after intervention [from $42(31.8 \%$ to $58(43.9 \%)]$. The proportion of workers with good practice in the intervention group increased from $40(30.3 \%)$ to $81(61.4 \%)$, while the control group increased slightly in practice from $26.5 \%$ to $37.1 \%$. There was a statistical significant difference in the change of knowledge and practice gained by the respondents in the intervention group, $\mathrm{p}=0.000$.

\subsection{Qualitative Data}

All the respondents were married and were mostly females who were aged more than fifty years and have spent more than five years in office. Several factors were identified as affecting the management of drugs in the state. These were grouped into the following themes:

\section{Strategic Factors}

Several factors were identified under this category. They included issues with the central medical stores like having quality drugs available, reduced lead time 
Table 5. Knowledge and practice score of either group of health workers before and after the intervention.

\begin{tabular}{|c|c|c|c|c|}
\hline Variable & \multicolumn{2}{|c|}{ Intervention group } & \multicolumn{2}{|c|}{ Control group } \\
\hline Knowledge Score (\%) & $\begin{array}{l}\text { Pre-intervention } \\
\quad(\mathrm{N}=132)\end{array}$ & $\begin{array}{l}\text { Post-intervention } \\
\quad(\mathrm{N}=132)\end{array}$ & $\begin{array}{l}\text { Beginning of study } \\
\quad(\mathrm{N}=132)\end{array}$ & $\begin{array}{l}\text { End of study } \\
(\mathrm{N}=132)\end{array}$ \\
\hline$<50$ & $101(76.5)$ & $35(26.5)$ & $90(68.2)$ & $74(56.1)$ \\
\hline \multirow[t]{2}{*}{$\geq 50$} & $31(23.5)$ & $97(73.5)$ & $42(31.8)$ & $58(43.9)$ \\
\hline & \multicolumn{2}{|c|}{$\mathrm{p}=0.000^{\star}$} & \multicolumn{2}{|c|}{$\mathrm{p}=0.065^{\star}$} \\
\hline Practice Score (\%) & $\begin{array}{l}\text { Pre-intervention } \\
\qquad(\mathrm{N}=132)\end{array}$ & $\begin{array}{l}\text { Post-intervention } \\
\qquad(\mathrm{N}=132)\end{array}$ & $\begin{array}{l}\text { Beginning of study } \\
\qquad(\mathrm{N}=132)\end{array}$ & $\begin{array}{l}\text { End of study } \\
\qquad(\mathrm{N}=132)\end{array}$ \\
\hline$<50$ & $92(69.7)$ & $51(38.6)$ & $97(73.5)$ & $83(62.9)$ \\
\hline \multirow[t]{2}{*}{$\geq 50$} & $40(30.3)$ & $81(61.4)$ & $35(26.5)$ & $49(37.1)$ \\
\hline & \multicolumn{2}{|c|}{$\mathrm{p}=0.000^{*}$} & \multicolumn{2}{|c|}{$\mathrm{p}=0.099^{*}$} \\
\hline
\end{tabular}

${ }^{*}$ McNemar test (Binomial distribution) was used, no $\chi^{2}$ value.

for collection of drugs, distance to the CMS, amongst other factors. All the respondents mentioned the lack of drugs in the CMS as the main problem, as stated by one of the respondents thus: “... the central medical store is not in function from the PHC s. They source their drugs from anywhere. These are some of the shortfalls because some of them will go to open market to source their drugs, this gives room for the presence of fake drugs in the public health care facilities". Lack of drugs in the CMS was attributed by some to be due to the non-release of funds for running the DRF, despite the commissioning of the drug logistics policy and building of a very big CMS. Another factor noted was the lack of political will by the last government in the state to release funds for this purpose. One of the respondents said “... though he launched the Anambra state drug logistics policy. Little or no funds were released to see to its implementation nor to stock up the built CMS in the state capital." Distance to the CMS was one of the problems noted by the person in charge of the PHCs at the ministry of the LGA as the reason why some health centers located far from the state capital do not purchase drugs from the CMS. The delay from the time of order of drugs to its supply was another reason noted by the same respondent.

\section{Operational Factors}

Most of the respondents noted issues in the health facilities as the main reason affecting their management of drugs in the PHCs; these include lack of trained hands handling drugs at the LGA and facility level. There are no pharmacists employed to work in the LGAs which directly oversees the functions of the PHCs as stated by a respondent thus, "... is the fact that they could not have pharmacists at that level, no pharmacists is there so some untrained hands are compelled to handle the drugs at that level with some unpleasant effects." This lack of trained hands makes them not to know what quantity to procure and also the right source for the purchase of drugs or how to distribute the drugs. This is what one of the respondents had to say: “... they do not keep to the correct drug distribution techniques/standards..." Where drugs are sourced from is another 
factor that affects the quality of the drug. One of the respondents stated that "procurement of drugs from the open market is the major source of drugs, because that is where they feel they get the drugs at the cheapest rate" Some of the health workers are ignorant of the fact that a lot of drugs in the open market are fake and since there is no quality control lab in the state to check some of this drugs out before giving it to patients, the market people will go ahead and give them whatever drug they have. Though another respondent said government is making efforts to set this. Lack of drug committee in the PHCs is another factor noted to affect drug management. This leaves the handling of drugs solely to the care of the officers in charge of the PHCs without their accounting for the drugs to anyone. This is what one of the respondents had to say: "there is nothing like drug committee. The drugs and therapeutic committee is not there..." Lack of good storage facilities was mentioned by most respondents as a factor affecting the practices of the health workers. One of the respondents had this to say: "The drugs are stored in conditions that you cannot say are conducive. Many of them do not have drug stores and the drugs are left on the counter..." Also the issue of lack of drug stock management tools in the facilities for keeping stock of drugs. The few facilities that had this were provided by the program in charge of the drug.

\section{Health System Factors}

Some health systems issues like the lack of DRF in the state and the political will of the government to support this affects the way drugs are handled in the state. One of the respondents had this to say, “... the present government is really interested and has approved and released funds for the start of a centralized $D R F$ in the state. Presently the CMS is being evacuated and cleaned up, ready for new drugs to be stocked up..." Another problem is the fact that the CMS is not given the free hand and funds to run on its own as this affects its maximum efficiency as it depends on getting permission from the ministry for funds for its maintenance. This is what one of the respondents have to say: “... if they make the CMS a directorate of its own, that will help to improve at least the storage conditions here and the management of the CMS'.

\section{Discussion}

The study sought to ascertain the factors affecting the knowledge and practice of drug management among primary health care workers involved in drug management in the primary health centers in Anambra state. The socio-demographic characteristics of the health care workers in the intervention and control groups were similar at baseline. There were no significant differences in the age, sex and cadre of health care workers and their years of experience. The health care workers showed similar age distribution with majority of them being over 35 years old in both groups. This was expected as this is the age at which the active working age group would have attained the position in their career to be in charge of the facility or to be the assistant to the person in-charge. Only very few of them (12.1\%) in intervention and $14.4 \%$ in control groups were aged below 35 
years. The mean age of the health workers was $43.3 \pm 7.92$. This finding is similar to the study done amongst drug managers in the PHCs, where the mean age was recorded to be $40.6 \pm 6.8$ [11]. Majority $(90.2 \%)$ of the intervention and (87.9\%) of the control groups have worked for more than 10 years with the median years of practice being 15 years. This can be attributed to the fact that some years need to be spent to get the position of officer-in-charge. This is similar to the findings of study on Decentralized delivery of Primary health care in Nigeria where staff had an average of 14 years of experience in primary health care [12].

Some activities in the state encourage good drug management practices and this study found that a high proportion of the health workers had good knowledge of some of such state activities like the availability and location of the central medical stores. While poor knowledge of others like owning a copy of essential drug formulary by the state and the practice of drug revolving fund (DRF) in the state also existed. It was necessary to ascertain this knowledge as it helped understand and explain the reasons for some of their drug management practices. This is similar to studies conducted in Nigeria and in other African countries like Kenya where training has been proven to improve the knowledge and practice of health workers [13] [14].

Some factors were identified by the respondents as responsible for the drug management practices of the health workers in the state, top of which was inadequate information that led to lack of knowledge of drug management. Then low interest of health workers for drug management which was different between the two groups and could be due to the few number of workers in the facilities, lack of good storage facilities and low funding. Post intervention, there was an increase in the responses of the intervention group which showed that they had a better knowledge of drug management and this could be attributed to the training they received. This contrasts with the findings from a study carried out to assess the HIV/AIDS drug management in Nigeria, where corruption, lack of political will, unavailability of drugs and lack of good storage conditions for drugs were identified [15]. This could be due to the parameters of interest assessed which varied from what was assessed by this study.

The in-depth interviews revealed lack of trained staff handling drugs in the PHCs as the main factor affecting the drug management. Other factors identified were lack of the following: DRF functional in the state, essential drugs stocked in the CMS, drug stock management tools provided by the state, trainings for the health workers who handle drugs. Unavailability of trained hands in the LGAs means no one to supervise the affairs of drugs in the PHCs which are directly under the care of the LGAs. This is because the few pharmacists employed at the state level cannot handle all the 264 PHCs in the State. The unavailability of drugs in the CMS encourages the PHC officer in-charge of drugs to source their drugs elsewhere and so they resort to the open market, thereby making them vulnerable to fake drugs with all its consequences. The importance of DRF is enormous as this will affect the whole drug management cycle with emphasis on getting cheaper prices for the same drugs due to bulk buying and also ensuring 
that good quality drugs are supplied as good quality control systems will be in place. This was similar to the study done in 6 geopolitical zones in Nigeria where it was shown that more than half of the health workers handling drugs were neither pharmacist nor trained for the job [16]. It is also similar to the findings from the qualitative aspects of this study which found such factors as financial constraint, inappropriate drug management, lack of pharmacists in handling drugs, non-implementation of essential drug list use and recommended that handling these could prevent drug stock outs. Lack of feedback information from the CMS was stated by some respondents as part of the factors affecting the management of drugs in the state. There is then the need to institutionalize a medicine and supplies information system to enable effective monitoring of the system and two way flow of information between the health workers and the pharmacists at the CMS. The development of Aide Memoire for drug management for use by the health workers will improve both knowledge and practice of drug management once they adhere to it, as shown by a study carried out in the rural communities of some countries where Aide Memoire for drug management was developed and they found a significant improvement in the drug management practices of the health workers [17].

In this study, there were no significant associations between the socio-demographic variables and the mean knowledge and practice score of drug management which was found to be poor before the intervention. The positive association between age of the control group and the mean practice score could be that their practice improved as they grew older and acquired more skills on the job. Post intervention, the mean knowledge score for the intervention group improved and was significant for cadre of staff, while the reverse was the case for the control group, where those with poor knowledge were more for age and years of practice. This shows that higher age does not translate to better practices. This is similar to the findings in the study in Uganda where there was no significant association between the participants' self-reported practices and knowledge question score [18].

\section{Conclusion}

In this study, age, sex, educational qualification, cadre of staff, years of practice and those trained in the past were factors associated with health workers' knowledge and practice of drug management but none of these were found to be predictors of good knowledge and practice of drug management. More studies are needed to identify factors associated with drug management in different settings and contexts for comparison purposes and to provide evidence that will guide informed policy formulations. This study hereby recommends that the development of an Aide Memoire for drug management will improve both knowledge and practice of drug management by the PHC workers.

\section{Conflicts of Interest}

The authors declare no conflicts of interest regarding the publication of this paper. 


\section{References}

[1] Bamako Initiative Programme in Nigeria (1994) The Bamako Imitative Unit.

[2] Malik, M., Azmi, M., Hassali, A., Shafie, A.A. and Hussain, A. (2018) Why Hospital Pharmacists Have Failed to Manage Antimalarial Drugs Stock-Outs in Pakistan? A Qualitative Insight. Malaria Research and Treatment, 2013, Article ID: 342843. https://doi.org/10.1155/2013/342843

[3] World Health Organization (1985) The Rational Use of Drugs. Report of the Conference of Experts Geneva: WHO. Resolution WHA54.

[4] Silumbe, R.S. (2011) Pharmaceutical Management and Prescribing Pattern of Antimalarial Drugs in the Public Health Facilities in Dar es Salaam, Tanzania. Master's Thesis, Muhimbili University of Health and Allied Sciences, Dar es Salaam.

[5] Chandani, Y., Takang, E., Allers, C. and McLaughlin, C. (2009) HIV/AIDS Drug Procurement and Supply Chain Management. From the Ground Up.

[6] JSI, UNICEF, USAID and WHO (2003) Guidelines for the Storage of Essential Medicines and Other Health Commodities.

http://www.who.int/3by5/en/storage_pocketguide.pdf

[7] Silumbe, R. and Kamuhabwa, A.R. (2013) Knowledge among Drug Dispensers and Antimalarial Drug Prescribing Practices in Public Health Facilities in Dar es Salaam. Drug, Healthcare and Patient Safety, 5, 181-189. https://doi.org/10.2147/DHPS.S50071

[8] Marieke, J.W., Langendam, M.W., Huitric, E. and Manissero, E. (2012) Knowledge of Tuberculosis-Treatment Prescription of Health Workers: A Systematic Review. European Respiratory Journal, 39, 1248-1255.

[9] Onwasigwe, C. (2010) Principles and Methods of Epidemiology. 2nd Edition, Dina El-Damak, Enugu.

[10] World Health Organization (2006) Handbook of Supply Management at First-Level Health Care Facilities.

http://www.who.int/management/resources/procurement/handbookforsupplymana gement.pdf

[11] World Bank (2019) Improving Primary Health Care Delivery in Nigeria: Evidence from Four States. World Bank Working Paper No. 187.

https://books.google.nl/books?isbn=0821383132

[12] Federal Ministry of Health, Nigeria, World Health Organization and Department for International Development and European Union (2009) National Drug Policy.

[13] Simon, S.M. (2013) Supply Chain Management Practices and Stock Levels of Essential Drugs in Public Health Facilities in Bungoma East Sub-County, Kenya. University of Nairobi, Nairobi.

[14] Nwankwo, B. and Sambo, M.N. (2018) Can Training of Health Care Workers Improve Data Management Practice in Health Management Information Systems: A Case Study of Primary Health Care Facilities in Kaduna State, Nigeria. The Pan African Medical Journal, 30, Article ID: 289.

[15] Shafiq, Y., Shaikh, B.T. and Kumar, R. (2011) Availability and Affordability of Essential Medicines: Exploring the Health Seeking Behaviours and Health Service Utilisation for Children under 5 Years Living in Squatter Settlement of Karachi, Pakistan. Journal of Ayub Medical College, 23, 132.

[16] Jenkins, R., Othieno, C., Okeyo, S., Aruwa, J., Wallcraft, J. and Jenkins, B. (2013) Exploring the Perspectives and Experiences of Health Workers at Primary Health Facilities in Kenya Following Training. International Journal of Mental Health Sys- 
tems, 7, Article No. 6. https://doi.org/10.1186/1752-4458-7-6

[17] Aronovich, Dana, Tien, M., Collins, E., Sommerlatte, A. and Allain, L. (2010) Measuring Supply Chain Performance: Guide to Key Performance Indicators for Public Health Managers. USAID, Arlington.

[18] Muyingo, S., David, V., Olupot, G., Ekochu, E., Sebagenzi, E., Kiragga, D., et al. (2000) Baseline Assessment of Drug Logistics Systems in 12 DISH Supported Districts (Draft Report). United States Agency for International Development, Uganda. 